\title{
Reducing "Screen-Time" and Promoting Self Care Activities among Overweight and Obese Pre-Adolescents: A Randomized Controlled Trial
}

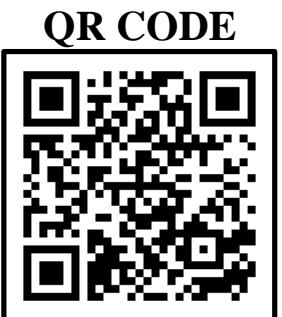

\section{SAHIL BANSAL ${ }^{* 1}\left(D\right.$, MEERA PRADHAN $^{2}$, ISHAN NAGAR', PRAVEEN KUMAR N.G. ${ }^{2}$}

INTRODUCTION: Pediatric obesity has been considered as one of the most serious public health challenges in the world.

AIM: To reduce "Screen-time" and promoting self care activities among overweight and obese pre-adolescents (aged 10-12 years) in India through proper intervention measures.

MATERIALS AND METHOD: Designed as a two-armed randomized controlled trial, 537 pre-adolescents aged 10-12 years were enrolled in this online study. Data was collected through a questionnaire (containing close-ended 26 questions). Pre- adolescents, whose BMI was classified as "overweight" and "obese were enrolled and randomly assigned (flip of coin) to the intervention group and control group. The intervention group were then given monthly online one-on-one sessions (to maintain confidentiality) by five standardized instructors. The study lasted for four months and a total of four individual sessions were provided to each child in the intervention group. Data was transferred into Excel for descriptive statistics, and analysed using SPSS version 22.0 using the paired t-test and multi variate logistic regression was applied keeping the significance value of $\mathrm{p}$ as $\leq 0.05$

RESULTS: A total of 537 pre- adolescents met the inclusion criteria. Among them, $270(50.3 \%)$ belonged to the intervention group and 267 (49.7\%) belonged to the control group. Majority of the pre- adolescents were males (59.4\%). In the intervention group, there were $61.8 \%$ overweight pre-adolescents, which reduced to $42.9 \%$, while in the control group, there were $89.5 \%$ overweight pre-adolescents, which reduced $9.8 \%$ and the difference between both the groups was observed to be significant $(\mathrm{p}=0.02)$.

CONCLUSION: Techniques used in the intervention group led to positive outcomes like weight loss and reduced screen time among the pre-adolescents which in turn, helped reduce the global burden of disease.

KEYWORDS: Obesity, Adolescents, Body Mass Index (BMI)

\begin{abstract}
INTRODUCTION
The epidemic of Pediatric obesity has been termed as "one of the most serious public health challenges of the $21^{\text {st }}$ century" by the WHO. ${ }^{1}$ Pre- adolescents, who serve as the future of any nation, are threatened by this epidemic. A presence of any preventable morbidity in these pre-adolescents can affect their overall general health which in turn increases the global burden of disease. As per a report by WHO, the prevalence of obesity among pre-adolescents and adolescents aged 5-19 years increased a whopping four times in between 1975 to $2016 .^{2}$
\end{abstract}

Sadly, there are two key contributors to obesity among pre- adolescents: poor diet and lack of physical activity which have led to preventable deaths, chronic disease(s), and economic health burden(both on the society as well as families).3,4 These two factors can be attributed to urbanization, as it leads to higher consumption of junk food and sedentary behavior. ${ }^{5}$ In addition, the onset of COVID-19 led to lockdowns and closure of schools, due to which pre-adolescents were forced to stay in their homes and attend classes online, which led to lesser physical activity.
Due to constant online activities, there is a risk of "Internet addiction", a relatively new form of dependency among pre-adolescents reported by the scientific community. ${ }^{6}$ The health effects of this addiction can have both mental and physical and both pre-adolescents and parents need to be aware that there is a need to "reduce screen time" and promote more physical activity. A healthy body is a gateway to systemic health as well as the bright future of the nation.

Due to the risk of obesity among pre-adolescents, a randomized controlled trial was undertaken to reduce "screen-time" and promoting self-care activities among overweight and obese pre-adolescents (aged 10-12 years) in India through proper intervention measures.

\section{MATERIAL AND METHODS}

The present study was designed as a two-armed randomized controlled trial, and after receiving an ethical approval, pre-adolescents (aged 10-12 years) were enrolled after taking their consent as well as their parent's/guardians consent to participate in the study.

(C) Sahil Bansal et al. This is an open access article distributed under the terms of the Creative Commons Attribution License CC-BY-NC 4.o, which permits unrestricted use, distribution and reproduction in any medium, provided the use is not commercial and the original author(s) and source are cited. Submitted on: 30-Jun-2021; Accepted on: 25-Jul-2021 
Participation was voluntary, and those enrolled were free to leave the study as per their wish. Enrolled preadolescents were based within India and participation links were shared with close associates (snowball sampling) as well on various online platforms. The enrolment period lasted for three weeks.

The study was conducted online, wherein after obtaining an online consent, data (self-reported) was collected through a questionnaire, which included the demographic data, height/weight, hours spent on pursuing physical activities at home, as well as time spent in front of the screen (Mobile/TV/Laptop). All questions were close-ended in nature. The questionnaire was tested on 20 pre- adolescents, whose results were not included in the present study. A total of 26 questions (in English language) were present in the questionnaire and it approximately took four minutes to complete.

Based on the inputs of the pre- adolescents, whose BMI was classified as "overweight" and "obese" were enrolled and randomly assigned (flip of coin) to the intervention group and control group. The intervention group were then given monthly online one-on-one sessions (to maintain confidentiality) by five standardized instructors. The study lasted for four months and a total of four individual sessions were provided to each child in the intervention group. The pre-adolescents were then again asked to fill the questionnaire. Access to data was only with the primary investigator who transferred the data into Excel, coded it and sent to the statistician for analysis using SPSS version 22.o. The tests applied were the paired t-test and multivariate logistic regression was applied keeping the significance value of $\mathrm{p}$ as $\leq 0.05$.

\section{RESULTS}

The demographic details of the pre-adolescents is depicted in table 1. Of a total of 1013 responses received, a total of 537(inclusion rate: $53.01 \%$ ) pre-adolescents met the inclusion criteria. Among them, 270(50.3\%) belonged to the intervention group and 267 (49.7\%) belonged to the control group. Majority of the preadolescents were males (59.4\%).

In the intervention group, there were $61.8 \%$ overweight pre-adolescents, which reduced to $42.9 \%$, while in the control group, there were $89.5 \%$ overweight preadolescents, which reduced $9.8 \%$ and the difference between both the groups was observed to be significant $(\mathrm{p}=0.02)$. Interestingly, in the control group, it was observed that only two(0.7\%) students became underweight and one (o.4\%) had a healthy BMI after completion of the study; in comparison, in the control group, ninety one $(33.7 \%)$ of the participants had achieved a healthy BMI $(\mathrm{p}=0.03)$. The median height was found to be $139.3 \mathrm{~cm}$ (pre-intervention group) and $140 \mathrm{~cm}$ (Control group) and the difference was found to be non-significant.

The median time spent on various activities and diet control by the pre-adolescents in depicted in table 2 . Significant reduction in time spent on phone were observed, followed by an increased time spent on selfcare activities and exercise in the intervention group. In the control group, the little changes were seen in their patterns and all changes were found to be insignificant. In the intervention group, diet control increased from $30 \%$ to $37.4 \%(\mathrm{p}=\mathrm{O} .02)$, an overall positive change in the pre-adolescents belonging to the intervention group was observed.

\begin{tabular}{|c|c|c|c|c|c|}
\hline \multirow{3}{*}{$\begin{array}{r}\text { Gender } \\
\text { Males } \\
\text { Females } \\
\text { Total } \\
\end{array}$} & \multicolumn{2}{|c|}{ INTERVENTON GROUP } & \multicolumn{2}{|c|}{ CONTROL GROUP } & p Value \\
\hline & \multicolumn{2}{|c|}{$\begin{array}{l}167(61.9 \%) \\
103(38.1 \%) \\
270(50.3 \%)\end{array}$} & \multicolumn{2}{|c|}{$\begin{array}{l}152(56.9 \%) \\
115(43.1 \%) \\
267(49.7 \%)\end{array}$} & - \\
\hline & $\begin{array}{c}\text { PRE- } \\
\text { INTERVENTION }\end{array}$ & $\begin{array}{c}\text { POST- } \\
\text { INTERVENTION }\end{array}$ & BASELINE & $\begin{array}{l}\text { POST STUDY } \\
\text { PERIOD }\end{array}$ & \\
\hline $\begin{array}{c}\text { Body Mass Index } \\
\text { Underweight }(<18.5) \\
\text { Healthy }\left(18.5^{-25}\right) \\
\text { Overweight }\left(25^{-<30}\right) \\
\text { Obese }(>30)\end{array}$ & $\begin{array}{c}\text { oо }(0 \%) \\
\text { oo(o\%) } \\
167(61.8 \%) \\
103(38.2 \%)\end{array}$ & $\begin{array}{c}\text { o6(2.2\%) } \\
91(33.7 \%) \\
137(42.9 \%) \\
36(21.2 \%)\end{array}$ & $\begin{array}{c}\text { oo }(0 \%) \\
\text { oo(o\%) } \\
28(10.5 \%) \\
239(89.5 \%)\end{array}$ & $\begin{array}{l}02(0.7 \%) \\
01(0.4 \%) \\
26(9.8 \%) \\
238(89.1 \%)\end{array}$ & $\begin{array}{c}0.88 \\
0.03^{*} \\
0.54 \\
0.02^{*}\end{array}$ \\
\hline Median Height (in cms) & \multicolumn{2}{|c|}{$139 \cdot 3$} & \multicolumn{2}{|c|}{140.0} & NS \\
\hline Median Weight (in kg) & 38.6 & 33.6 & 34.1 & 34.2 & NS \\
\hline
\end{tabular}

Table 1. Demographic Details of the Pre-Adolescents 


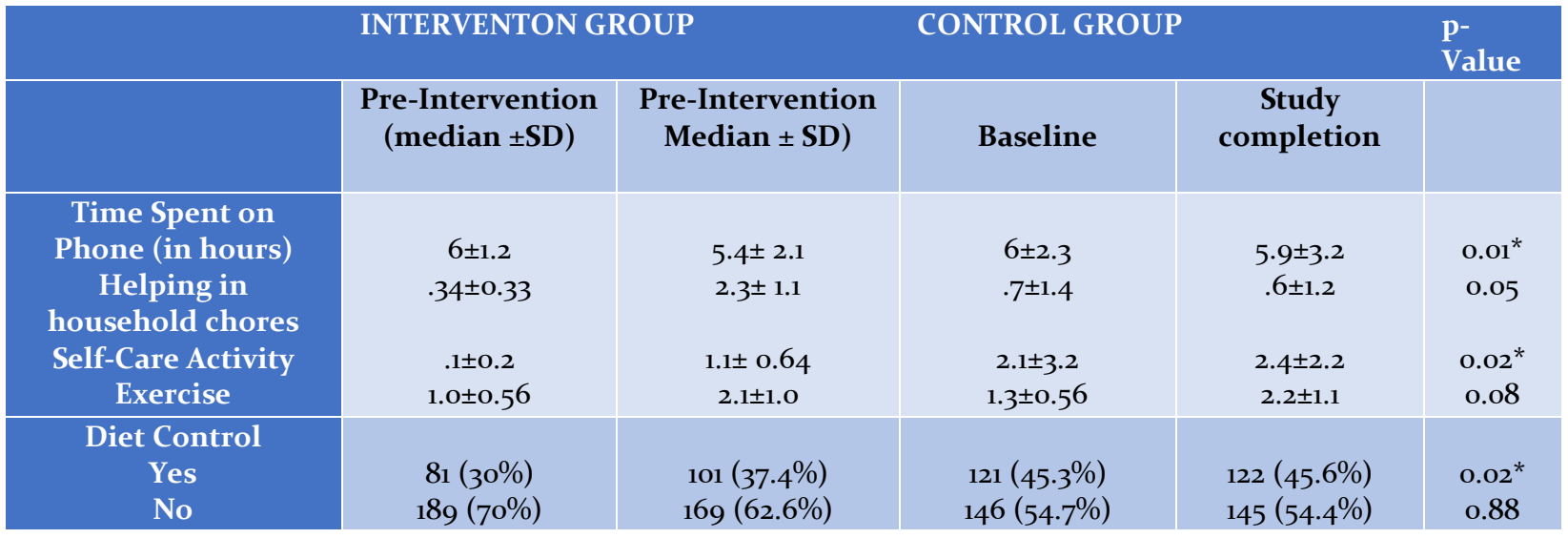

Table 2. Median Time Spent on Various Activities and Diet Control by the Pre-Adolescents

The results of the multivariate logistic regression stated that reduced screen time was significantly associated with weight reduction $(\mathrm{p}=\mathrm{o.o1})$ and physical $\operatorname{activity}(\mathrm{p}=0.04)$ among pre-adolescents in the intervention group; encouraging the use of such intervention programmes in the future (Table 3 ).

\begin{tabular}{c|c|c|c|}
\hline $\begin{array}{c}\text { SCREEN } \\
\text { TIME }\end{array}$ & $\begin{array}{c}\text { SCREEN } \\
\text { TIME }\end{array}$ & $\begin{array}{c}\text { WEIGHT } \\
\text { REDUCTION }\end{array}$ & $\begin{array}{c}\text { PHYSICAL } \\
\text { ACTIVITY }\end{array}$ \\
\hline $\begin{array}{c}\text { Screen } \\
\text { time }\end{array}$ & $\mathrm{a}^{*}$ & 0.01 & 0.04 \\
\hline $\begin{array}{c}\text { Weight } \\
\text { Reduction }\end{array}$ & 0.01 & $\mathrm{a}^{*}$ & 0.01 \\
\hline $\begin{array}{c}\text { Physical } \\
\text { Activity }\end{array}$ & 0.08 & .0 .01 & $\mathrm{a}^{*}$ \\
\hline
\end{tabular}

Table 3. Multivariate Logistic Regression between Screen Time, Weight Reduction and Physical Activity ( $\mathrm{a}^{*}$ : Constant)

\section{DISCUSSION}

The ongoing pandemic has been quite hard on school attending students. As the world slowly prepared to unlock and return to normalcy, the decision on keeping schools closed is perhaps, in the best interest of the students. However, confined to the walls of their homes, these students who were once overtly active have been made to sit and attend online classes and limit their physical activity, which inturn has probably increased their snacking due to constant availability of food.

It has also been reported that obesity is identified as an independent risk factor for COVID-19 disease severity and obese children may experience a more severe COVID-19 trajectory which might include the need for respiratory support. ${ }^{7}$ The overall obesity of $53.01 \%$ was high as compared to pre-covid era estimations of $19.3 \% \%^{8}$ and $\sim 7-8 \%,{ }^{9}$ respectively.
In the present study, significant reductions in weight (61.8\% to $42.9 \%)$ and obesity $(38.2 \%$ to $21.2 \%)$ was observed among pre-adolescents and the findings are similar to trials conducted by Aguilar-Cordero MJ et al. ${ }^{10}$ and Larsen LM et al. ${ }^{11}$ Many outcomes data have been reported from research studies that have examined exercise alone, exercise plus dietary restriction, or dietary restriction alone to determine strategies for weight loss. In line with the intervention strategies adopted by the present study, Donnelly et al. demonstrated weight loss with exercise in a group of 141 overweight or obese (BMI $31 \mathrm{~kg} / \mathrm{m}^{2}$ ) men and women in the Midwest Exercise Trial 2; the amount of activity to achieve this weight loss was again greater than the general exercise recommendations for health.

Diet control increased from $30 \%$ to $37.4 \%$ in the intervention group and scientific evidence states it is important to recognize the challenge of monitoring dietary intake and exercise intensity and duration over the long term. In contrast to popular belief, the evidence linking exercise and its contribution to significant weight loss and further weight maintenance is not firmly established; and diet control plays an important role in the same. ${ }^{12}$ We hypothesise that as a result of staying at home due to the pandemic, the preadolescents they were tempted to eat junk/high cholesterol preparations made at home and hence, could not follow proper diet control.

The inclusion of a control group helped compare and analyze the effectiveness of the interventions. In good interests of the control group, the results of the present study was shared by them online by the primary investigator (41.0\% attendance rate) and they were encouraged to take up remedial measures to prevent weight related issues in them. The control group shall be followed up after six months again to assess their 
progress. Due to the self-reported nature of the data, there could be a probability of under/over reporting of the data by the respondents, but it was addressed by ensuring complete confidentiality of the data to the parents and the children. Due to the pan India presence of the study and the tests applied, we can safely state that the results of the present study can be generalized for other populations.

\section{CONCLUSION}

The various techniques used in the intervention group led to positive outcomes like weight loss and reduced screen time among the pre-adolescents which in turn, helped reduce the global burden of morbidity. We recommend the need for further studies using the same intervention techniques and methodology by colleagues so that the findings of the present study can be further strengthened/refuted through their valuable findings.

\section{REREFENCES}

1. Romanelli R, Cecchi, N, Carbone MG, Dinardo M, Gaudino G, del Giudice EM, et al. Pediatric obesity: prevention is better than care. Ital $\mathrm{J}$ Pediatr. 2020;46:103. https://doi.org/10.1186/s13052-020-0o868-

7

2. WHO. Obesity and overweight. (Online Article). Available from: https://www.who.int/healthtopics/obesity\#tab=tab 1. [Last Accessed $17^{\text {th }}$ January, 2021].

3. Friedemann C, Heneghan C, Mahtani K, Thompson M, Perera R, Ward AM. 2012. Cardiovascular disease risk in healthy pre-adolescents and its association with body mass index: systematic review and meta-analysis. BMJ : British Medical Journal 2012;345:e4759. https://doi.org/10.1136/bmj.e4759

4. Hamilton D, Dee A, Perry IJ. 2018. The lifetime costs of overweight and obesity in childhood and adolescence: a systematic review. Obesity Reviews 19: $452-63$.

5. Popkin BM, Gordon-Larsen P. The nutrition transition: worldwide obesity dynamics and their determinants. Int J Obes Relat Metab Disord. 2004;28(Suppl 3):S2-9

6. Moreno M, Jelenchick L, Christakis D. Problematic internet use among older adolescents: A conceptual framework. Computers and Human Behavior. 2013:1879-87.

7. Lighter J, Phillips M, Hochman S, Sterling S, Johnson $\mathrm{D}$, Francois F, Stachel A. Obesity in patients younger than 60 years is a risk factor for Covid-19 hospital admission. Clinical Infectious Diseases. 2020 2020:ciaa415. https://doi.org/10.1093/cid/ciaa415.

8. Ranjani H, Mehreen T S, Pradeepa R, Anjana RM, Garg R, Anand K, Mohan V. Epidemiology of childhood overweight \& obesity in India: A systematic review. Indian J Med Res. 2016;143:160-74. https://doi.org/10.4103/0971-5916.180203

9. Nguyen PH, Scott S, Headey D, Singh N, Tran LM, Menon P, et al. (2021) The double burden of malnutrition in India: Trends and inequalities (20062016). PLoS ONE 16(2): e0247856. https://doi.org/10.1371/journal.pone.0247856

10. Aguilar-Cordero MJ, Rodríguez-Blanque R, LeonRíos X, Expósito Ruiz M, García García I, SánchezLópez AM. Influence of Physical Activity on Blood Pressure in Children With Overweight/Obesity: A Randomized Clinical Trial. Am J Hypertens. 2020;33(2):131-6. https://doi.org/10.1093/ajh/hpz174.

11. Larsen LM, Hertel NT, Mølgaard C, Christensen RD, Husby S, Jarbøl DE. Early intervention for childhood overweight: A randomized trial in general practice. Scand J Prim Health Care. 2015;33(3):184-90. https://doi.org/10.3109/02813432.2015.1067511.

12. Cox CE. Role of Physical Activity for Weight Loss and Weight Maintenance. Diabetes Spectr. 2017;30(3):157-6o. https://doi.org/10.2337/ds17-0o13.

\section{AUTHOR AFFILIATIONS: $\left({ }^{*}\right.$ Corresponding Author)}

1. MBBS Graduate, Consultant Medical Practitioners, Bhopal, India (Dr. Sahil Bansal: https://orcid.org/oooo-0002-2406-1014)

2. MD, Orthopaedics, Consultant Specialists, Naveen Nursing Centre, Indore, MP, India

Source of support: Nil, Conflict of interest: None declared 